Virginia Commonwealth University vCU Scholars Compass

2016

News Stories of Intimate Partner Violence: An Experimental Examination of Participant Sex, Perpetrator Sex, and Violence Severity on Seriousness, Sympathy, and Punishment Preferences

Matthew W. Savage

University of Kentucky

Jennifer A. Scarduzio

University of Kentucky

Kate Lockwood Harris

University of Minnesota Twin Cities

Kellie E. Carlyle

Virginia Commonwealth University

Pondowthiseffand additional works at: http://scholarscompass.vcu.edu/hcpr_pubs iversity of Kentucky

Part of the Medicine and Health Sciences Commons

(C) 2017 Taylor \& Francis

Downloaded from

http://scholarscompass.vcu.edu/hcpr_pubs/13

This Article is brought to you for free and open access by the Department of Health Behavior and Policy at VCU Scholars Compass. It has been accepted for inclusion in Health Behavior and Policy Publications by an authorized administrator of VCU Scholars Compass. For more information, please contact libcompass@vcu.edu. 


\section{Health Communication

\section{News Stories of Intimate Partner Violence: An Experimental Examination of Participant Sex, Perpetrator Sex, and Violence Severity on Seriousness, Sympathy, and Punishment Preferences}

Matthew W. Savage, Jennifer A. Scarduzio, Kate Lockwood Harris, Kellie E. Carlyle \& Sarah E. Sheff

To cite this article: Matthew W. Savage, Jennifer A. Scarduzio, Kate Lockwood Harris, Kellie E. Carlyle \& Sarah E. Sheff (2017) News Stories of Intimate Partner Violence: An Experimental Examination of Participant Sex, Perpetrator Sex, and Violence Severity on Seriousness, Sympathy, and Punishment Preferences, Health Communication, 32:6, 768-776, DOI: 10.1080/10410236.2016.1217453

To link to this article: http://dx.doi.org/10.1080/10410236.2016.1217453

曲 Published online: 27 Sep 2016.

Submit your article to this journal \lceil

Ш Article views: 99

View related articles $\nearrow$

View Crossmark data \lceil 


\title{
News Stories of Intimate Partner Violence: An Experimental Examination of Participant Sex, Perpetrator Sex, and Violence Severity on Seriousness, Sympathy, and Punishment Preferences
}

\author{
Matthew W. Savage ${ }^{a}$, Jennifer A. Scarduzioa, Kate Lockwood Harris ${ }^{b}$, Kellie E. Carlylec, and Sarah E. Sheffa

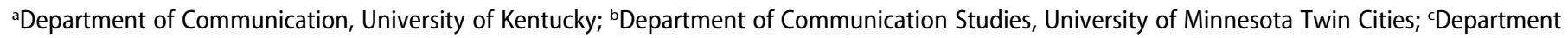 \\ of Health Behavior and Policy, Virginia Commonwealth University
}

\begin{abstract}
This study experimentally examines the effects of participant sex, perpetrator sex, and severity of violence on perceptions of intimate partner violence (IPV) seriousness, sympathy toward the victim, and punishment preferences for the perpetrator. Participants $(N=449)$ were randomly assigned to a condition, exposed to a composite news story, and then completed a survey. Ratings of seriousness of IPV for stories with male perpetrators were significantly higher than ratings of seriousness for stories with female perpetrators. Men had significantly higher sympathy for female victims in any condition than for male victims in the weak or strong severity of violence conditions. Men's sympathy for male victims in the fatal severity of violence condition did not differ from their sympathy for female victims. Women had the least sympathy for female victims in the weak severity condition and men in the weak or strong severity conditions. Women reported significantly higher sympathy for female victims in the strong and fatal severity of violence conditions. Women's ratings of sympathy for male victims in the fatal severity of violence condition were statistically indistinguishable from any other group. Participants reported stronger punishment preferences for male perpetrators and this effect was magnified among men. Theoretical implications are presented with attention provided to practical considerations about support for public health services.
\end{abstract}

Intimate partner violence (IPV) is a pervasive community health concern. Approximately 1.5 million women and 837,000 men are victims of IPV in the United States (U.S.) each year (Cronholm, Fogarty, Ambuel, \& Harrison, 2011). Although the majority of IPV victims are heterosexual women, IPV can occur in any relational context and socioeconomic, religious, cultural, or sexual orientation group (Centers for Disease Control and Prevention [CDC], 2016; World Health Organization [WHO], 2012). The term IPV can refer to an isolated act of violence or to multiple, repeated acts of violence (CDC, 2014). These acts can include physical or sexual violence, emotional or psychological abuse, and controlling behaviors (WHO, 2012). Studies of how entertainment media impact aggression and violence are common (e.g., Anderson et al., 2010; Wright, Tokunaga, \& Kraus, 2016), whereas studies of how news stories impact perceptions of IPV are less frequent despite the fact that news portrayals of IPV tend to cast individuals as responsible. In fact, content analyses of IPV news stories consistently reveal that incidents are often separated from any consideration of social or cultural contexts (Carll, 2003; Carlyle, Scarduzio, \& Slater, 2014; Carlyle, Slater, \& Chakroff, 2008; Sellers, Desmarais, \& Tirotti, 2014). Other research has established that news stories reduce the public's feelings of responsibility about IPV (Carlyle, Orr,
Savage, \& Babin, 2014). In summary, individuals perceive IPV to be an individual or relationship issue, not a social or cultural problem, and their feelings of personal responsibility about IPV situations outside of their own relationships are frequently minimal, if any.

Furthermore, information communicated in news stories has an impact on individual perceptions of IPV. Sotirovic (2003) found that information in the media helps individuals explain social problems, such as crime and welfare. Additionally, in a germinal article, Gottleib and Ickes (1978) stated that what is included or excluded in news media can "lead to changes in the attributor's perception of the situation," which "can generalize into a change in the person's attitude and/or behavior with respect to this situation" (p. 263). Journalists, thus, have potential to impact public understandings of IPV, especially by providing context for individual episodes. To maximize that impact, we first need to identify how readers perceive IPV incidents in the news based only on descriptions of those incidents.

Past research explored how participants' attributions of responsibility, sympathy, and punishment preferences are impacted by news story portrayals of IPV. For example, Palazzolo and Roberto (2011) illustrated that certain emotions, such as sympathy and anger, helped determine punishment 
preferences and responsibility, and the emotions varied depending on the information provided (e.g., victim having an affair). Moreover, research has found that IPV news stories about female perpetrators present women as abnormal, extreme, or deviant-especially when the violence is severe (Carlyle, Scarduzio, et al., 2014). Since people learn and make judgments about IPV based on the news, it is important to study how readers perceive elements of IPV in that venue, such as whether perceptions about IPV vary for male and female perpetrators and when the reported severity of violence varies. To that end, this study offers an experimental examination of IPV composite news stories where sex of the perpetrator and severity of violence are manipulated. We examine the effects of these variables, as well as participant sex, on ratings of seriousness of IPV as a public health concern, sympathy for the victim, and punishment preferences for the perpetrator. Content analyses have determined that news stories most often present IPV as a one-time or episodic event (Carlyle et al., 2008). Yet a preferred, thematic framing of IPV situations would establish that IPV is frequently a pattern of behavior rather than a onetime incident. To develop effective thematic framing in news stories, we need to first understand readers' specific perceptions of the facts presented in episodic framing. Therefore, this study intends to understand readers' specific perceptions of the facts presented in a news story that employs episodic framing. By identifying these perceptions, research may help journalists to better understand that thematic framing of IPV must intervene in readers' automatic perceptions, independent of the facts of an incident of violence.

\section{Intimate Partner Violence}

IPV is defined as physical violence, sexual violence, stalking, and psychological aggression by a current or former intimate partner (Breiding, Basile, Smith, Black, \& Mahendra, 2015). Breiding et al. (2014) reported CDC findings from the 2011 U.S. National Intimate Partner Violence and Sexual Violence survey indicating that that $22.3 \%$ of women and $14.0 \%$ of men have been victims of severe physical violence in their lifetime. While IPV commonly refers to physical or sexual abuse, psychological abuse and emotional abuse almost always accompany physical and sexual abuse (Campbell \& Manganello, 2006). Past work called for collective action to prevent IPV, efforts to hold perpetrators responsible for their crimes, and continued rigorous evaluation of IPV (CDC, 2016). The prevalence and seriousness of IPV calls for investigations into how readers perceive the sex of the perpetrator and severity of IPV in news stories when all other factors are held constant.

\section{Media Portrayals of Intimate Partner Violence}

News stories have framed IPV as an individual-level problem, which has implications for readers' perceptions of perpetrators, victims, and IPV as a societal and public health issue (Bullock, 2007). Widespread media coverage of IPV began in 1976, focusing on battered women and battered women's shelters (Gillespie, Richards, Givens, \& Smith, 2013), and recent research suggests that media presentations of IPV impacts perceptions and communication about IPV (Harris,
Palazzolo, \& Savage, 2012; Scarduzio, Carlyle, Harris, \& Savage, 2016). As mentioned, Carlyle et al. (2008) found that the majority of IPV news stories were written using episodic framing, presenting issues as single events instead of as a broader social problem. Given the frequent use of episodic framing in the representation of IPV news, there is a misconception that IPV is primarily about a perpetrator and victim rather than a community concern (Bullock \& Cubert, 2002; Meyers, 1996). Though scholars have called for news stories to use thematic framing and present IPV as a social problem, they have not yet examined the extent to which gender-related dynamics should be part of those framings.

Past studies consistently reported that news stories about IPV leave readers with an inaccurate view of the roles of male and female perpetrators and victims. Lindsay-Brisbin, DePrince, and Welton-Mitchell (2014) examined 213 IPV news stories published in 2008 Colorado newspapers and found that one-third of the articles used frames that could lead to misperceptions about victim blame regarding male and female perpetration. An early and consistent focus on female victims using these frames has also had negative implications on perceptions of male victims. For example, in a study of media portrayals comparing perceptions of male and female IPV victims, Hines and Douglas (2010) reported that when the victim was male, participants perceived the situation as less severe and blamed the man less. Despite the perception differences regarding male and female perpetrators, research indicates that men and women are both victims and perpetrators.

\section{Sex and Gender of IPV Perpetration}

Men and women have diverse experiences as victims and perpetrators of IPV. Although women are more likely than men to report IPV, past research indicates that men are also victims and face many of the same consequences as women-including injury, substance abuse, and chronic mental illness (Coker et al., 2002). Indeed, past studies reported that between $25 \%$ and $50 \%$ of IPV victims are male (Catalano, 2007; Tjaden \& Thoennes, 2000).

Research identified the prevalence of female to male IPV and suggested that the framing of IPV has dismissed male victimization (Hines \& Douglas, 2010). Additionally, recent research on male victims focuses on help-seeking behaviors and available resources (Douglas \& Hines, 2011; Douglas, Hines, \& McCarthy, 2012; Tsui, 2014). These studies illustrated that services for male victims are underdeveloped compared to services for female victims-especially shelter services.

Men are more likely than women to perpetrate IPV, though moderate-intensity woman-to-man violence does occur (Nayback-Beebe \& Yoder, 2012). Furthermore, in a recent study, $95.4 \%$ of women admitted to perpetrating emotional or verbal violence and $28.3 \%$ admitted to committing at least one act of physical violence (Spidel, Greaves, Nicholls, Goldenson, \& Dutton, 2013). Though women commit IPV, the physical injuries they inflict on males tend to be less severe than the physical injuries males inflict on females (Dobash \& Dobash, 2004). 
Although females perpetrate IPV, scholars disagree about how to interpret these acts. Some suggest that women and men commit IPV for similar reasons and with similar consequences (Dutton, 2011). Other scholars suggest that women's acts of IPV should be understood as self-defense (Houry et al., 2008). Different assumptions yield these conflicting readings of IPV perpetration. Those who analyze IPV at the individual level tend to conclude that males and females commit IPV at similar rates (Straus, 2004). In contrast, those who situate IPV in a larger social framework argue that men's violence against women perpetuates systemic inequalities in ways that women's violence against men does not (DeKeseredy \& Dragiewicz, 2007; Johnson, 2011). The first group of scholars focuses on the sex of perpetrators, and the second group of scholars focuses on how IPV perpetration is gendered, that is, how society determines what it means to be masculine or feminine. This debate about whether to understand IPV through the lens of sex or gender shows up not only in scholarly publications, but also in everyday talk about IPV (Harris et al., 2012; Scarduzio et al., 2016). In the present study, we underscore the impact of these differing assumptions by manipulating only the biological sex of the perpetrator and victim. In so doing, we approximate what would be likely to happen if journalists did not include information about the gendered, social dynamics of IPV and focused only on the sex of the individuals involved in the IPV incident.

\section{Severity of Violence}

Severity of violence is an important factor to consider because participants' perceptions about IPV perpetrators may vary depending on the type of violence that is employed. Research determined that participants had harsher punishment preferences when IPV perpetrators used severe violence and engaged in alcohol consumption (Lane \& Knowles, 2000). In another study, the severity of violence only affected whether participants blamed the perpetrator when another factor, such as verbal aggression, was present (Witte, Schroeder, \& Lohr, 2006).

Importantly, research determined that journalists present the same acts of violence differently for male and female perpetrators. For example, in a recent content analysis of IPV news stories, Sellers et al. (2014) found that when the same type of IPV occurred (i.e., homicide) female perpetrators were more often portrayed as acting in self-defense than male perpetrators. Perceptions of IPV also differ when male and female perpetrators use severe violence. For example, female perpetrators who use severe violence, such as killing their partner, are perceived as abnormal or socially deviant (Carlyle, Scarduzio, et al., 2014). Further, male perpetrators who use severe violence are depicted more frequently in news stories because they are more likely to use severe violence than female perpetrators, and thus their behavior is normalized (see Carlyle et al., 2008). However, a recent content analysis determined that even though male perpetrators are portrayed more frequently, female-perpetrated IPV in news stories was overall more severe when compared to maleperpetrated IPV, and more than half of the total news stories reported severe violence (Sellers et al., 2014). Collectively, these findings suggest that when a male perpetrator and a female perpetrator commit the same act, news stories may present male-perpetrated and female-perpetrated IPV situations differently. Moreover, these studies demonstrate the communication dynamics that play into how IPV is portrayed in the news.

\section{The Present Study}

To examine public perceptions about male and female perpetrators, we created a composite news story depicting a fictional episode of IPV between a man and a woman in a heterosexual context and manipulated the sex of the perpetrator and the severity of violence across conditions. We also investigated how participants differed in their responses based on their sex. To our knowledge, only Witte et al. (2006) have investigated participant sex and found that men are more likely to use victim behavior as a reason to attribute greater responsibility to female victims. Given emergent empirical research on responses to IPV news stories, we explored the effects of perpetrator sex, participant sex, and violence severity on IPV seriousness, sympathy toward the victim, and punishment preferences for the perpetrator.

\section{IPV Seriousness}

News stories have the potential to promote increased public support and involvement in prevention efforts, and participants' rating of IPV seriousness as a public health concern can be used to evaluate this construct. Given the media's influence on public responsiveness to social issues like IPV, as well as the emphasis on increasing public awareness as a strategy for IPV prevention (Campbell \& Manganello, 2006; Carlyle, Orr, Savage, \& Babin, 2014; Wolfe \& Jaffe, 1999), investigating changes in IPV seriousness caused by media portrayals is prudent. Because of the prevalence of IPV, even incremental changes in ratings of IPV seriousness may have an impact on the public health burden caused by IPV. Thus, we examine how news stories impact participants' perceptions of IPV seriousness to advance scholarship that promotes collective societal action.

\section{Sympathy}

Research demonstrates that audiences' concern for the distress of a victim in an IPV news story is important. Palazzolo and Roberto (2011) found that sympathy mediated the relationship between the perceptions of an IPV victim portrayed in a news story and perpetrator punishment preferences, but anger did not. Other scholarship has investigated the relationship between sympathy toward the victim and prosocial behavior to intervene or report IPV. For example, Carlyle, Orr, et al. (2014) found a positive relationship between sympathy and prosocial behavior and also acknowledged a debate about mediators and temporal ordering. Studies like these illustrate the utility in examining sympathy for the victim as a way to understand the emotionality of the reader following exposure to an IPV news story. By assessing sympathy, we focus on a salient and important feeling toward the victim and avoid conflating these perceptions with factors used to determine culpability (Esqueda \& Harrison, 2005). 


\section{Punishment Preferences}

Favored consequences for the perpetrator are an important outcome to examine to understand the effects of IPV media portrayals (Graham, Weiner, \& Zucker, 1997; Palazzolo \& Roberto, 2011; Pavlou \& Knowles, 2001). Within the IPV literature, these favored consequences are referred to as punishment preferences and include a range of attitudinal, judgmental, and judicial preference variables that describe an action of interest following exposure to a media portrayal (Carlyle, Orr, et al., 2014). In the present study, the punishment preference of interest is to place the perpetrator in jail. Stalans and Lurigio (1995) used this outcome in examinations of public preferences for court handling of IPV cases. Investigating whether to put the perpetrator in jail aligns with theories of motivational sequence relating to aggressive acts (Weiner, 1995) and is particularly relevant to IPV media portrayals. For example, Palazzolo and Roberto (2011) found that this punishment preference is likely to result from specific attribution and emotion processes following exposure to print stories of IPV. Although their study found a positive relationship between both anger and sympathy and preference for putting the IPV perpetrator in jail, less is known about how the sex of the perpetrator and level of severity impact punishment preferences.

Examining preferences to place the perpetrator in jail in this context is warranted because it is retributive against the perpetrator, thus tapping into underlying notions of responsibility. Other possible outcomes, such as mandatory counseling for the couple, could implicate culpability for both the victim and the perpetrator. In addition, the preference to place an IPV perpetrator in jail following exposure to a print story provides valuable insight into how media portrayals of violence could affect public opinion about criminal justice policy preferences. Investigating punishment preferences in this way stands to contribute to the IPV literature by focusing less on how individuals make punishment decisions in a courtroom and more on the larger social context in which those decisions are made.

\section{Methods}

\section{Research Participants}

Four hundred forty-nine participants were recruited from undergraduate communication courses in the United States. The sample included more women (64.2\%) than men (35.8\%). The majority (82.0\%) of participants were White, $9.4 \%$ were Latino/a, 2.7\% were Black or African-American, 4.2\% Asian or Asian-American, $0.2 \%$ Native Hawaiian or Pacific Islander, $0.4 \%$ Native American or Alaskan Native, and 10.5\% preferred not to answer or skipped this question. The mean age was 21.8 years $(S D=3.29)$. Seniors comprised $49.0 \%$ of the sample, juniors $33.0 \%$, sophomores $13.6 \%$, freshmen $1.3 \%$, and other $3.1 \%$.

\section{Procedure and Design}

A composite IPV news article similar to a print or online news story was created based on characteristics reported in a nationally representative content analysis of IPV newspaper coverage (Carlyle et al., 2008). Following what was most typical in that analysis, the composite story depicts a heterosexual couple where the perpetrator inflicts physical rather than sexual, psychological, verbal, or economic violence. An example of the composite story from one condition:

Woman murdered; Man held in custody.

By Lawrence Wilson.

Phoenix, AZ-Michael Sampson was arrested last night for allegedly assaulting his wife. According to the affidavit filed by police, Phoenix police officers arrived at the Sampson residence around 9 pm after receiving a call from neighbors who reported hearing loud noises and yelling.

Two officers found Mr. Sampson, 39, and a woman in the living room. The woman, who was later confirmed as his wife, Julie Sampson, 35, was bleeding from a wound on her head. Mr. Sampson reported that he and his wife had been arguing when things escalated and he hit her with a vase from a nearby table.

Ms. Sampson was taken to the hospital and died later that evening. Officers took Mr. Sampson into custody and he is currently being held at the Maricopa County Detention Center pending arraignment.

Conditions varied based on (1) pronoun and perpetration description to manipulate sex of the perpetrator and (2) violence severity (weak, strong, fatal). This is only one example.

Information about the perpetrator and the level of violence was manipulated in the composite article to create six experimental conditions using a $2 \times 3$ design. The six experimental conditions crossed perpetrator sex (male/female) and the severity of violence (weak/strong/fatal). Sex of the perpetrator was manipulated using pronouns and a description of perpetration. Severity of violence was manipulated using common types of violence reported in typical IPV news articles (Carlyle et al., 2008). In the weak violence condition, the perpetrator hits the victim with a household object and leaves a cheekbone bruise that results in a hospital visit and release. In the strong violence condition, the perpetrator hits the victim with a household object that inflicts a bleeding head wound and results in a hospital visit and release. In the fatal condition, the perpetrator hits the victim with a household object that inflicts a bleeding head wound and results in a hospital visit and death. After creating the stories, a panel of professors with professional journalism experience reviewed and edited them.

Participants were randomly assigned to one of the six experimental conditions. After participants read the story, participants completed an online self-administered questionnaire that contained measures of all dependent variables, as well as measures for a larger study. To ensure no systematic biases in responses due to fatigue or order effects, the placement of perpetrator and victim items randomly alternated so that half the research participants responded to items regarding the perpetrator first while the other half responded about the victim first. Manipulation checks included multiple items that were analyzed to ensure participants correctly attuned to perpetrator sex and the severity of violence. Participants correctly identified the perpetrator sex in $98 \%$ of cases, $\chi^{2}(1)=371.56$, $p<.001$. Participants in each severity of violence condition 
significantly differed in an expected manner when comparing their perceptions of the severity of the victim's injury, $F$ $(2)=289.46, p<.001$. These results indicate that the independent variables were successfully manipulated in the desired manner in all conditions. The university's institutional review board approved all procedures.

\section{Dependent Variables}

\section{IPV Seriousness}

Four items measured participants' perception of the seriousness of IPV as a public health concern. The items asked whether "IPV is a [serious] public health concern." Serious was replaced with "severe," as well as with "inconsequential" and "mild" (reverse-coded). Response categories ranged from 1 (strongly disagree) to 6 (strongly agree). The development of these items was informed by previous research on the topic of prosocial responses to IPV (Carlyle, 2007). Reliability in this study was acceptable $($ alpha $=.82)$.

\section{Sympathy}

Sympathy toward the victim was measured with a 4-item scale adapted from Dillard and Peck (2000). After reading the news story, participants rated how strongly they felt each emotion (e.g., "How much do you feel each of the following emotions toward the man in the story [sympathy, empathy, compassion, concerned]") on a scale from 1 (do not feel the emotion the slightest bit) to 5 (feel the emotion very strongly). Estimates of reliability in the present study were good $($ alpha $=.88)$.

\section{Punishment Preferences}

Punishment preferences were assessed using one item developed and validated by Stalans and Lurigio (1995) and used in recent IPV investigations (e.g., Palazzolo \& Roberto, 2011). Participants rated how much they preferred the following punishment: "Put the perpetrator in jail." Response categories ranged from 1 (strongly do not prefer) to 6 (strongly prefer).

\section{Results}

A series of three $2 \times 2 \times 3$ factorial analysis of variance (ANOVA) procedures assessed the effect of participant sex, sex of the perpetrator, and violence severity on each outcome. In all analyses (with one exception noted below) Levene's test of equality of error variances showed that homogeneity of variance assumptions was not violated. For all analyses, the exploratory nature of the investigation warranted examining the interactive effects of participant sex, perpetrator sex, and severity on outcomes. For clarity, we use men and women as nouns to describe participants and male and female as adjectives to describe the sex of perpetrators and victims.

First, an ANOVA examined ratings of seriousness. Results indicated no significant interaction effects. Significant main effects were present for violence severity, $F(2,424)=63.58$, $p<.01, \eta_{\mathrm{p}_{2}}^{2}=.23$, and for perpetrator sex, $F(1,424)=23.48$, $p<.01, \eta_{\mathrm{p}}{ }^{2}=.07$. Results of the main effect for severity were examined using a Scheffé post hoc test $(p<.05)$ and indicated that those exposed to the weak severity $(M=3.63, S D=.94)$, strong severity $(M=4.19, S D=.97)$, and fatal violence severity conditions $(M=4.94, S D=.85)$ all significantly differed from one another. That is, perceptions of the seriousness of IPV increased linearly with the severity of IPV. Results of the main effect for perpetrator sex indicated that participant ratings of seriousness for stories with male perpetrators $(M=4.52, S D=.97)$ were significantly higher than their ratings with female perpetrators $(M=3.98, S D=1.08)$.

Second, an ANOVA examined participants' sympathy toward the victim. Results indicated that the three-way interaction between participant sex, sex of the perpetrator, and violence severity was significant, $F(2,423)=4.85, p<.01$, $\eta_{\mathrm{p}}{ }^{2}=.02$. The interaction was probed and analyzed in lieu of significant main effects for violence severity, $F(2,423)=14.57$, $p<.001, \eta_{\mathrm{p}}{ }^{2}=.06$, and for perpetrator sex, $F(1,423)=36.29$, $p<.001, \eta_{\mathrm{p}}{ }^{2}=.08$. The three-way interaction was divided into two $2 \times 3$ ANOVAs examining sex of the perpetrator and level of violence on ratings of sympathy toward the victim at each level of participant sex. That is, one two-way ANOVA only included men and the other two-way ANOVA only included women.

One $2 \times 3$ ANOVA investigated sex of the perpetrator and level of violence on ratings of victim sympathy among men. Results indicated that the two-way interaction between perpetrator sex and violence severity was significant, $F(2,150)=3.26$, $p<.05, \eta_{\mathrm{p}}{ }^{2}=.04$. This interaction was probed in lieu of significant main effects for violence severity, $F(2,150)=6.80$, $p<.01, \eta_{\mathrm{p}}{ }^{2}=.08$, and for perpetrator sex, $F(1,150)=13.86$, $p<.001, \eta_{\mathrm{p}}{ }^{2}=.09$. The interaction was analyzed with a followup one-way ANOVA conducted on a six-level variable created by crossing perpetrator sex and violence severity on ratings of victim sympathy amongst men. A Scheffé post hoc test $(p<.05)$ revealed that men reported the least sympathy for male victims of weak $(M=2.12, S D=.84)$ or strong $(M=2.32, S D=1.16)$ levels of violence severity. Men had significantly more sympathy for female victims of weak $(M=3.24, S D=1.16)$, strong $(M=3.04, S D=1.01)$, or fatal $(M=3.39, S D=1.12)$ levels of violence severity. Men's ratings of sympathy for male victims in the fatal condition $(M=3.33, S D=.97)$ did not differ from their ratings of sympathy for female victims in any violence condition. In sum, men were more sympathetic toward female victims of violence than toward male victims of violence, unless male victims were killed.

The other $2 \times 3$ ANOVA investigated sex of the perpetrator and level of violence on ratings of victim sympathy amongst women. Results indicated that the two-way interaction between perpetrator sex and violence severity was significant, $F(2,273)=3.77, p<.05, \eta_{\mathrm{p}}{ }^{2}=.03$. This interaction was probed in lieu of interpreting significant main effects for violence severity, $F(2,273)=10.99, p<.001, \eta_{\mathrm{p}}{ }^{2}=.08$, and for perpetrator sex, $F(1,273)=26.35, p<.001, \eta_{\mathrm{p}}{ }^{2}=.09$. The interaction was analyzed with a follow-up one-way ANOVA conducted on a six-level variable crossing perpetrator sex and violence severity on ratings of victim sympathy amongst women. A Scheffé post hoc test $(p<.05)$ revealed a pattern where women reported significantly higher sympathy for female victims in the strong $(M=3.72, S D=1.12)$ and fatal violence severity $(M=3.75, S D=1.04)$ conditions. Women had significantly lower sympathy for female victims in the weak $(M=2.75, S D=1.16)$ and male victims in the weak 


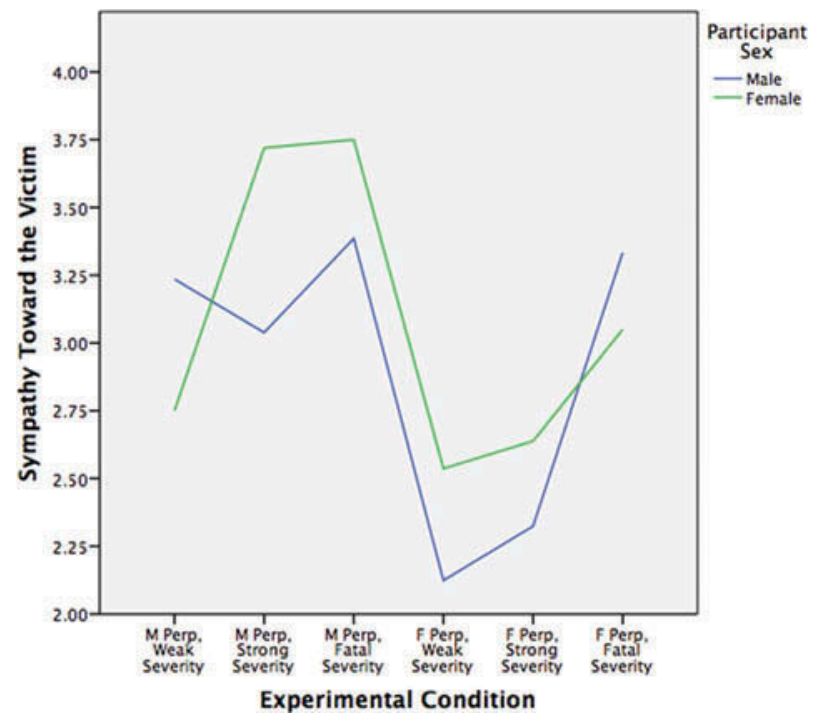

Figure 1. Men's and women's ratings of sympathy toward the victim by condition.

$(M=2.54, S D=.93)$ and strong $(M=2.64, S D=1.06)$ violence severity conditions. Women's ratings of sympathy for male victims in the fatal $(M=3.05, S D=1.10)$ condition did not differ from any other group. In sum, women had significantly higher sympathy for female victims in only the strong and fatal severity of violence conditions, wherein their sympathy toward male victims remained unaffected when the male was killed. Figure 1 illustrates the three-way interaction findings regarding sympathy for victims.

Third, an ANOVA examined participants' punishment preferences. Levene's test of equality of error variances indicated that the homogeneity of variance assumption was violated, $F$ $(11,422)=2.94, p<.05$, although ANOVA is generally robust to this violation. Results indicated no significant interaction effects. Significant main effects were present for violence severity, $F(2,422)=142.53, p<.01, \eta_{\mathrm{p}}{ }^{2}=.26$, perpetrator sex, $F(1$, $422)=74.34, p<.01, \eta_{\mathrm{p}}{ }^{2}=.09$, and participant sex, $F(1$, $422)=9.03, p<.05, \eta_{\mathrm{p}}{ }^{2}=.01$. Results of the main effect for violence severity were examined using a Scheffé post hoc test $(p<.05)$ and indicated that those exposed to the weak $(M=2.75, S D=1.54)$, strong $(M=3.42, S D=1.57)$, and fatal $(M=4.90, S D=1.23)$ violence severity conditions all significantly differed from one another in their punishment preferences to send the perpetrator to jail. Results of the main effect for perpetrator sex indicated that participants' punishment preferences for male perpetrators $(M=4.17, S D=1.57)$ were significantly higher than their punishment preferences for female perpetrators $(M=3.17, S D=1.70)$. Results of the main effect for participant sex indicated that men had significantly higher punishment preferences $(M=3.76, S D=1.70)$ than women $(M=3.61, S D=1.71)$.

\section{Discussion}

This study examined how a composite IPV news story that varied perpetrator sex and severity of violence impacted participants' perceptions of seriousness of IPV as a public health concern, sympathy for victims, and punishment preferences for perpetrators. Results showed that severity played a large role in participants' ratings of IPV seriousness. Even in the weak violence condition, participants still rated IPV as serious. Content analyses of news stories have shown that IPV with low levels of violence is not frequently depicted in new stories (e.g., Carlyle, Scarduzio, et al., 2014; Sellers et al., 2014). However, the current study finds that presentations of low-severity violence may still impact the individuals reading news stories.

Participants' ratings of seriousness of IPV for stories with male perpetrators were significantly higher than their ratings of seriousness for stories with female perpetrators. Participants may be viewing IPV through a systemic lens and may see male perpetrators' violence toward females as part of social inequalities on the basis of gender. These same findings may also explain why male victims often do not seek help (Douglas \& Hines, 2011) or feel unsupported when they do seek assistance (Douglas et al., 2012; Tsui, 2014). That is, men are less likely to seek help when they are the victims of IPV because they believe that others will look down on them if they are not able to protect themselves, whether physically, financially, or emotionally. This point of discussion is in line with research demonstrating that men "struggle to reconcile their victimization with a masculine identity" (Tsui, Cheung, \& Leung, 2010, p. 770). Scholars also argue that male victims of IPV may hide their victimization to avoid humiliation, judgment, or even reverse accusations. These findings underscore this previous research by showing that media viewers do, indeed, downplay the seriousness of violence that men experience.

Previous work has suggested that caricatured portrayals of violent females may contribute to the perception that male victimization is unimportant. For example, Carlyle, Scarduzio, et al. (2014) determined that media portrayals of female perpetrators as abnormal or extreme may diminish the seriousness of female-perpetrated IPV. In the present experimental study, female perpetrators were portrayed identically to male perpetrators and results still demonstrated differences in seriousness based on perpetrator sex. This finding extends existing work by demonstrating that incredulous portrayals of female perpetrators are not the only news factor that discounts male victims. Indeed, news stories in which only the "facts" of the episode are presented still result in different perceptions of severity. As we discuss more in practical implications for the study, this finding amplifies the importance of news stories going beyond description of an isolated incident, or episodic framing, to provide contextual, thematic framing of IPV incidents.

Results regarding sympathy showed that men and women had different levels of sympathy for the victim based on perpetrator sex and severity of violence. Men had significantly higher sympathy for female victims in any condition than male victims in the weak or strong severity of violence conditions. Men's sympathy for male victims in the fatal severity of violence condition did not differ from their sympathy for female victims. Said differently, the male victim had to be killed for men to have a similar level of sympathy toward male victims as female victims. This pattern of findings indicates that men have significantly higher sympathy for female victims than male victims, unless a female perpetrator kills a male victim. As noted earlier, men's different responses to male and female victims may reflect an 
understanding of the gendered, systemic dynamics of IPV. That is, men may be influenced by the media's presentation of maleperpetrated violence as more common and more severe than female-perpetuated violence (Carlyle, Scarduzio, et al., 2014). Additionally, men's ratings of sympathy for male victims only increased significantly in the fatal severity of violence condition, suggesting that men may believe that a female perpetrator is not able to cause as much harm as a male perpetrator if the violence does not result in death. The difference between men and women participants' levels of sympathy for victims, though, may also be explained by benevolent sexism: an underlying attitude that suggests men should protect women (Glick \& Fiske, 2001). Though sympathy for victims may be a positive social good, benevolent sexism ultimately keeps unequal gender systems in place (Barreto \& Ellemers, 2005).

Women had the least sympathy for female victims in the weak severity condition and men in the weak or strong severity conditions. Women reported significantly higher sympathy for female victims in the strong and fatal severity of violence conditions. Women's ratings of sympathy for male victims in the fatal severity of violence condition were statistically indistinguishable from any other group. This pattern of findings for women deviates from those reported by men in two important ways. First, men had relatively high ratings of sympathy for female victims in all severity of violence conditions, whereas women had significantly lower sympathy for female victims in the weak severity condition when compared to the strong and fatal severity of violence conditions. Second, men had a statistically significant increase in sympathy for male victims when they were killed, whereas women's sympathy was unaffected.

Recent research found that when a female perpetrates IPV, participants are likely to believe that she acts in selfdefense (Scarduzio et al., 2016). In the present study, it is plausible that women believed the female perpetrator was actually defending herself against violence the male initiated, and therefore women may have been less sympathetic to the male victim. Taylor and Sorenson (2005) determined that victims were perceived to be responsible for the violence when their behavior was "provocative or negligent" (p. 9), and male victims were likely to be perceived as more responsible for IPV than female victims. Similarly, other research found that participants had more negative attitudes toward male victims than female victims (Arnocky \& Vaillancourt, 2014). The present study extends this research by finding that men had consistently higher sympathy for female victims than male victims unless the male victim was killed, and women had significantly higher sympathy for female victims in only the strong and fatal severity of violence conditions wherein their sympathy toward male victims remained unaffected when the male was killed. Interestingly, women felt little sympathy toward a female victim who experienced low severity of violence. One potential explanation for this finding aligns with Snyder and Ickes's (1985) "weak" situations. That is, when the severity of violence is low or "weak" the women could attribute the male perpetrator's behavior to a variety of factors-not just the severity of the violence-and this may be why they feel less sympathy.
Results regarding punishment preferences were strongly impacted by the severity of violence presented in the news story and moderately impacted by sex. The large effect size for severity of violence based on significant differences between the weak, strong, and fatal levels of violence severity indicated that the more severe the condition of violence presented, the higher was the increase in ratings of punishment preferences for the perpetrator. These findings correspond with and add to previous scholarship examining punishment preferences. Palazzolo and Roberto (2011) found that negative information about an IPV perpetrator in a news story (e.g., history of domestic violence, drunkenness) was positively related to punishment preferences. Our results reveal similar findings with regard to severity of violence. Adding to this line of research, these results offer a nuanced understanding of differences in punishment preferences due to participant sex and perpetrator sex. First, participants reported higher punishment preferences for male perpetrators than for female perpetrators. Second, although this effect was small, men had higher punishment preferences than women. These findings, considered in conjunction with the results concerning seriousness, highlight potential contributing factors explaining why female-perpetrated violence is considered less harmful and important than male-perpetrated violence.

\section{Practical Implications}

The first practical implication of this study relates to media framing. Episodic framing supplies the audience with a preconceived opinion, which the audience members then apply to their reality (Carlyle et al., 2008). The present study used episodic framing in the composite news story because it is more common in portrayals of IPV in the media. The findings revealed that when episodic framing was employed participants felt less sympathy for male victims than female victims and had higher punishment preferences for male perpetrators than female perpetrators. Thematic framing, on the other hand, occurs when a news story is made to seem as a smaller piece of a larger problem. Journalists should attempt to present IPV stories using thematic framing to help readers gain more informed perspectives. In particular, journalists using thematic framing could usefully incorporate information about how gender-the social meanings ascribed to sex-influences perceptions of IPV.

The second practical implication of this study relates to the types of IPV services available. The findings suggest that male victims may perceive that they will not receive as much sympathy as female victims. Research has determined that men who seek services usually do not receive the help they needespecially at shelters (see Tsui, 2014). On the other hand, participants' lower punishment preferences for female perpetrators may create problems for addressing IPV in its multiple forms. Public health officials have successfully called attention to the prevalence of men's violence against women, but have been unsuccessful in addressing situations of female perpetration or male victimization. Binary understandings of sex may limit media and education's ability to address the complex gendered dynamics that infuse IPV, regardless of the sex of perpetrators and victims. 


\section{Limitations and Future Directions}

The participants in the study were undergraduate students, and while data demonstrate that IPV is experienced among adults of all ages, drawing results from young adults prevents the results from being completely generalizable to a larger population. However, IPV is extremely common in college-age individuals (Tjaden \& Thoennes, 2000), and this study offers interesting findings of an experimental design where internal validity superseded generalizability. Future studies should evaluate the impact of similar variables in IPV news coverage using samples of adults outside college. Furthermore, this experiment was conducted online, which could have contributed to the findings. although we accounted for frequently cited online methodological concerns (Birnbaum, 2004) by monitoring drop-out rate and preventing repeated participation. Indeed, online and traditional studies in the social sciences usually reach the same conclusions and evidence suggests that Internet, paper-and-pencil, and faceto-face methods in the social sciences produce similar results in college-age and adult samples (Skitka \& Sargis, 2006).

Another limitation is that this study focused on cross-sex or heterosexual IPV perpetration. Future research should explore seriousness, sympathy, punishment preferences, and other important outcomes in the context of IPV in LGBTQ (lesbian, gay, bisexual, transgendered, and queer and/or questioning) relationships. An important question for future scholars is whether male victims still receive lower ratings of sympathy when another man perpetrates the violence. Similarly, do punishment preferences for female perpetrators increase when they are perpetrating violence against another woman? A cursory search of the IPV literature demonstrates a dearth of empirical evidence within same-sex relationships.

Three final areas for future research relate to media framing and processing of mass media IPV portrayals. As mentioned, this study used only episodic framing in the composite news story presented to participants. Future research should use both episodic and thematic framing to determine whether participants' sympathy for victims and punishment preferences for perpetrators vary when IPV is presented as a larger social problem. Researchers can explore whether thematic framing increases perceptions of IPV seriousness as a public health concern even for less severe forms of IPV. Indeed, this study contributes to a growing body of literature that can be used to specify an overall model of IPV media portrayal processing. The present study moves us closer to this goal while also offering many novel theoretical and practical contributions. Previous research (e.g., Palazzolo \& Roberto, 2011) can inform the specification of a robust model of IPV mass media portrayal processing. Doing so is a next step for communication and media psychology scholars.

\section{Conclusion}

This study examined how perceptions of seriousness, sympathy for the victim, and punishment preferences for the perpetrator varied when the sex of the perpetrator, the sex of the victim, and the severity of violence were manipulated in a composite IPV news story. This study shows that perceptions of IPV are impacted by media portrayals of news stories in specific ways.
First, participants' perception of the seriousness of IPV as a public health concern is impacted by the severity of violence. Second, when stories portray male perpetrators, differences in the sympathy that men and women feel toward the victim due to perpetrator sex and severity of violence reveal noteworthy emotion-processing incongruences. Third, punishment preferences for male and female perpetrators are impacted by the severity of violence and the sex of the participant reading the composite news story. Given that IPV is an important public health issue with individual, relational, and societal implications, these findings underscore the importance of continuing to examine how news stories shape perceptions of IPV and the impact such perceptions may have on support for prevention initiatives.

\section{References}

Anderson, C. A., Shibuya, A., Ihori, N., Swing, E. L., Bushman, B. J., Sakamoto, A., ... Saleem, M. (2010). Violent video game effects on aggression, empathy, and prosocial behavior in Eastern and Western countries: A meta-analytic review. Psychological Bulletin, 136, 151173. doi:10.1037/a0018251

Arnocky, S., \& Vaillancourt, T. (2014). Sex differences in response to victimization by an intimate partner: More stigmatization and less help-seeking among males. Journal of Aggression, Maltreatment \& Trauma, 23, 705-724. doi:10.1080/10926771.2014.933465

Barreto, M., \& Ellemers, N. (2005). The burden of benevolent sexism: How it contributes to the maintenance of gender inequalities. European Journal of Social Psychology, 35, 633-642. doi:10.1002/ejsp.270

Birnbaum, M. H. (2004). Human research and data collection via the Internet. Psychology, 55, 803-832. doi:10.1146/annurev.psych.55.090902.141601

Breiding, M. J., Basile, K. C., Smith, S. G., Black, M. C., \& Mahendra, R. R. (2015). Intimate partner violence surveillance: Uniform definitions and recommended data elements, version 2.0. Atlanta, GA: National Center for Injury Prevention and Control, Centers for Disease Control and Prevention.

Breiding, M. J., Smith, S. G., Basile, K. C., Walters, M. L., Chen, J., \& Merrick, M. T. (2014). Prevalence and characteristics of sexual violence, stalking, and intimate partner violence victimization-National intimate partner violence and sexual violence survey, United States, 2011. Retrieved from www.cdc.gov/mmwr/preview/mmwrhtml/ss6308a1.htm Bullock, C. F. (2007). Framing domestic violence fatalities: Coverage by Utah newspapers. Women's Studies in Communication, 30, 34-63. doi:10.1080/07491409.2007.10162504

Bullock, C. F., \& Cubert, J. (2002). Coverage of domestic violence fatalities by newspapers in Washington state. Journal of Interpersonal Violence, 17, 475-499. doi:10.1177/0886260502017005001

Campbell, J. C., \& Manganello, J. (2006). Changing public attitudes as a prevention strategy to reduce intimate partner violence. Journal of Aggression, Maltreatment \& Trauma, 13, 13-39. doi:10.1300/ J146v13n03_02

Carll, E. K. (2003). News portrayal of violence and women: Implications for public policy. American Behavioral Scientist, 46, 1601-1610. doi: $10.1177 / 0002764203254616$

Carlyle, K. E. (2007). Media representations of intimate partner violence: Exploring the mediating role of attributions and emotions (Doctoral dissertation). Retrieved from OhioLINK ETD (osu1186342473).

Carlyle, K. E., Orr, C., Savage, M. W., \& Babin, E. A. (2014). News coverage of intimate partner violence: Impact on prosocial responses Media Psychology, 17, 451-471. doi:10.1080/15213269.2014.931812

Carlyle, K. E., Scarduzio, J. A., \& Slater, M. D. (2014). Media portrayals of female perpetrators of intimate partner violence. Journal of Interpersonal Violence, 29, 2394-2417. doi:10.1177/0886260513520231

Carlyle, K. E., Slater, M. D., \& Chakroff, J. L. (2008). Newspaper coverage of intimate partner violence: Skewing representations of risk. Journal of Communication, 58, 168-186. doi:10.1111/j.1460-2466.2007.00379.x

Catalano, S. (2007). Intimate partner violence in the United States [Electronic version]. Washington, DC: U.S. Department of Justice, 
Office of Justice Programs, Bureau of Justice Statistics. Retrieved from http://www.ojp.usdoj.gov/bjs/intimate/ipv.htm

Centers for Disease Control and Prevention. (2014). Intimate partner violence: Fact sheet. Retrieved from http://vetoviolence.cdc.gov/index. $\mathrm{php} /$ fact-sheet-intimate-partner-violence/

Centers for Disease Control and Prevention. (2016). Intimate partner violence. Retrieved from http://www.cdc.gov/ViolencePrevention/inti matepartnerviolence/index.html

Coker, A. L., Davis, K. E., Arias, I., Desai, S., Sanderson, M., Brandt, H. M., \& Smith, P. H. (2002). Physical and mental health effects of intimate partner violence for men and women. American Journal of Preventive Medicine, 23, 260-268. doi:10.1016/S0749-3797(02)00514-7

Cronholm, P. F., Fogarty, C. T., Ambuel, B., \& Harrison, S. L. (2011). Intimate partner violence. American Family Physician, 83, 1165-1172.

DeKeseredy, W. S., \& Dragiewicz, M. (2007). Understanding the complexities of feminist perspectives on woman abuse. Violence Against Women, 13, 874-884. doi:10.1177/1077801207304806

Dillard, J. P., \& Peck, E. (2000). Affect and persuasion: Emotional responses to public service announcements. Communication Research, 27, 461-495. doi:10.1177/009365000027004003

Dobash, R. P., \& Dobash, R. E. (2004). Women's violence to men in intimate relationships: Working on a puzzle. British Journal of Criminology, 44, 324-349. doi:10.1093/bjc/azh026

Douglas, E. M., \& Hines, D. A. (2011). The help seeking experiences of men who sustain intimate partner violence: An overlooked population and implications for practice. Journal of Family Violence, 26, 473-485. doi:10.1007/s10896-011-9382-4

Douglas, E. M., Hines, D. A., \& McCarthy, S. C. (2012). Men who sustain female-to-male partner violence: Factors associated with where they seek help and how they rate those resources. Violence and Victims, 27, 871-894. doi:10.1891/0886-6708.27.6.871

Dutton, D. G. (2011). Rethinking domestic violence. Vancouver, BC, Canada: UBC Press.

Esqueda, C. W., \& Harrison, L. A. (2005). The influence of gender role stereotypes, the woman's race, and level of provocation and resistance on domestic violence culpability attributions. Sex Roles, 53, 821-834. doi:10.1007/11199s-005-8295-1

Gillespie, L. K., Richards, T. N., Givens, E., \& Smith, M. D. (2013). Framing intimate partner victimization: Why the media's spin matters in newspaper coverage of femicide. Violence Against Women, 19, 222 244. doi:10.1177/1077801213476457

Glick, P., \& Fiske, S. T. (2001). An ambivalent alliance: Hostile and benevolent sexism as complementary justifications for gender inequality. American Psychologist, 56, 109-118. doi:10.1037/0003-066X.56.2.109

Gottleib, A., \& Ickes, W. (1978). Attributional strategies of social influence. In J. H. Harvey, W. Ickes, \& R. F. Kidd (Eds.), New directions in attribution research (pp. 261-296). Hillsdale, NJ: Lawrence Erlbaum Associates.

Graham, S., Weiner, B., \& Zucker, G. S. (1997). An attributional analysis of punishment goals and public reactions to O.J. Simpson. Personality and Social Psychology Bulletin, 23, 331-346. doi:10.1177/0146167297234001

Harris, K. L., Palazzolo, K. E., \& Savage, M. W. (2012). "I'm not sexist, but ...": How ideological dilemmas reinforce sexism in talk about intimate partner violence. Discourse \& Society, 23, 643-656. doi:10.1177/0957926512455382

Hines, D., \& Douglas, E. (2010). Intimate terrorism by women towards men: Does it exist? Journal of Aggression, Conflict, and Peace Research, 2, 36-56. doi:10.5042/jacpr.2010.0335

Houry, D., Rhodes, K. V., Kemball, R. S., Click, L., Cerulli, C., McNutt, L. A., \& Kaslow, N. J. (2008). Differences in female and male victims and perpetrators of partner violence with respect to WEB scores. Journal of Interpersonal Violence, 23, 1041-1055. doi:10.1177/0886260507313969

Johnson, M. P. (2011). Gender and types of intimate partner violence: A response to an anti-feminist literature review. Aggression and Violent Behavior, 16, 289-296. doi:10.1016/j.avb.2011.04.006

Lane, B., \& Knowles, A. (2000). Community attitudes to domestic violence: Attributions of responsibility and suggested punishments related to alcohol consumption and level of violence. Psychiatry, Psychology, and Law, 7, 51-58. doi:10.1080/13218710009524970

Lindsay-Brisbin, J., DePrince, A. P., \& Welton-Mitchell, C. (2014). Missed opportunities: Newspaper reports of domestic violence.
Journal of Aggression, Maltreatment \& Trauma, 23, 383-399. doi:10.1080/10926771.2014.896839

Meyers, M. (1996). News coverage of violence against women: Engendering blame. Newbury Park, CA: Sage.

Nayback-Beebe, A. M., \& Yoder, L. H. (2012). The lived experience of a male survivor of intimate partner violence: A qualitative case study. Medsurge Nursing, 21, 89-96.

Palazzolo, K. E., \& Roberto, A. J. (2011). Media representations of intimate partner violence and punishment preferences: Exploring the role of attributions and emotions. Journal of Applied Communication Research, 39, 1-18. doi:10.1080/00909882.2010.536843

Pavlou, M., \& Knowles, A. (2001). Domestic violence: Attributions, recommended punishments and reporting behavior related to provocation by the victim. Psychiatry, Psychology and Law, 8, 76-85. doi:10.1080/13218710109525006

Scarduzio, J. A., Carlyle, K. E., Harris, K. L., \& Savage, M. W. (2016). "Maybe she was provoked": Exploring gender stereotypes about male and female perpetrators of intimate partner violence. Violence Against Women. Online First. doi:10.1177/1077801216636240

Sellers, B. G., Desmarais, S. L., \& Tirotti, M. (2014). Content and framing of male- and female-perpetrated intimate partner violence in print news. Partner Abuse, 5, 259-278. doi:10.1891/1946-6560.5.3.259

Skitka, L. J., \& Sargis, E. G. (2006). The Internet as psychological laboratory. Annual Review of Psychology, 57, 529-555. doi:10.1146/ annurev.psych.57.102904.190048

Snyder, M., \& Ickes, W. (1985). Personality and social behavior. In G. Lindzey \& E. Aronson (Eds.), Handbook of social psychology: (Vol. 2, 3rd ed., pp. 883-947). New York, NY: Random House.

Sotirovic, M. (2003). How individuals explain social problems: The influences of media use. Journal of Communication, 53, 122-137. doi:10.1111/j.1460-2466.2003.tb03009.x

Spidel, A., Greaves, C., Nicholls, T. L., Goldenson, J., \& Dutton, D. G. (2013). Personality disorders, types of violence, and stress responses in female who perpetrate intimate partner violence. Psychology, 4, 5-11. doi:10.4236/psych.2013.49A1002

Stalans, L. J., \& Lurigio, A. J. (1995). Public preferences for the court's handling of domestic violence situations. Crime \& Delinquency, 41, 399-413. doi:10.1177/0011128795041004002

Straus, M. A. (2004). Prevalence of violence against dating partners by male and female university students worldwide. Violence Against Women, 10, 790-811. doi:10.1177/1077801204265552

Taylor, C. A., \& Sorenson, S. B. (2005). Community-based norms about intimate partner violence: Putting attributions of fault and responsibility into context. Sex Roles, 53, 573-589. doi:10.1007/s11199-005-7143-7

Tjaden, T., \& Thoennes, N. (2000). Prevalence and consequences of male-to-female and female-to-male intimate partner violence as measured by the national violence against women survey. Violence Against Women, 6, 142-161. doi:10.1177/10778010022181769

Tsui, V. (2014). Male victims of intimate partner abuse: Use and helpfulness of services. Social Work, 59(2), 121-130. doi:10.1093/sw/swu007

Tsui, V., Cheung, M., \& Leung, P. (2010). Help-seeking among male victims of partner abuse: Men's hard times. Journal of Community Psychology, 38, 769-780. doi:10.1002/jcop.20394

Weiner, B. (1995). Judgments of responsibility: A foundation for a theory of social conduct. New York, NY: Guilford Press.

Witte, T. H., Schroeder, D. A., \& Lohr, J. M. (2006). Blame for intimate partner violence: An attributional analysis. Journal of Social and Clinical Psychology, 25, 647-667. doi:10.1521/jscp.2006.25.6.647

Wolfe, D. A., \& Jaffe, P. G. (1999). Emerging strategies in the prevention of domestic violence. Future of Children, 9, 133-144. doi:10.2307/ 1602787

World Health Organization. (2012). Global and regional estimates of violence against women: Prevalence and health effects of intimate partner violence and non-partner sexual violence. World Health Organization. Retrieved from http://www.who.int/reproductivehealth/publications/vio lence/9789241564625/en/

Wright, P. J., Tokunaga, R. S., \& Kraus, A. (2016). A meta-analysis of pornography consumption and actual acts of sexual aggression in general population studies. Journal of Communication, 66, 183-205. doi:10.1111/ jcom.12201 